\title{
Influência de folhas e lesões na base de estacas herbáceas no enraizamento de goiabeira da seleção 8501-9
}

\section{Influence of leaf and base lesion of herbaceous cutting in the guava rooting of the selection $8501-9$}

\author{
Patricia Helena Santoro $^{1 *}$; Adriana Yatie Mikami ${ }^{1}$; \\ Silvia Graciele Hülse de Souza'; Sérgio Ruffo Roberto²
}

\section{Resumo}

Com o objetivo de avaliar o potencial de enraizamento da seleção 8501-9 de goiabeira utilizou-se estacas herbáceas com 10-12 cm de comprimento em duas formas de preparo (corte simples sem lesão e exposição do câmbio) e três intensidades de supressão das folhas (sem folhas, com folhas cortadas ao meio e folhas intactas). O delineamento experimental foi inteiramente casualizado com cinco repetições em arranjo fatorial $2 \times 3$, com dez estacas por parcela. Após tratamento com AIB as estacas foram colocadas para enraizamento em caixas plásticas $(44 \times 30 \times 7 \mathrm{~cm})$ contendo casca de arroz carbonizada, em câmara de nebulização. Após 78 dias avaliou-se a retenção foliar, a sobrevivência das estacas, o número de estacas enraizadas e de raízes, o comprimento e as massas fresca e seca das raízes. A interação entre lesão e presença de folhas não foi significativa, indicando que estes fatores agem de forma independente em relação aos fatores estudados. A supressão das folhas resultou em morte das estacas. A exposição do câmbio não proporcionou vantagens no enraizamento de estacas herbáceas. As estacas com um par de folhas inteiras apresentaram maiores massas fresca e seca de raízes em relação às estacas com folhas cortadas, já as estacas sem folhas não apresentaram formação de raízes, sendo a presença de folhas fundamental para a promoção do enraizamento.

Palavras-chave: Psidium guajava L, reguladores vegetais, propagação vegetal

\begin{abstract}
With the objective of evaluate the potential of rooting of the selection of guava tree 8501-9 were using herbaceous cutting with $10-12 \mathrm{~cm}$ of length in two make of the prepared (simple cut without lesions and cambium exposition), and three suppression intensity of the leaves (without leaves, with half leaves and intact leaves). The experimental design was completely randomized with five repetitions in factorial arrangement $2 \times 3$, with ten cutting for parcel. After the preparation with IBA the cutting had been placed to rooting in plastic box $(44 \times 30 \times 7 \mathrm{~cm})$ with carbonized rice hulls, in camera of nebulization. After 78 days, evaluated the leaf retention, survive of the cutting, the number of cutting roots and of roots, the length and fresh and dry mass of the roots. The interaction between lesions and presence of leaves was not significant, indicating like this factors act in independent form in relation the study factors. The leaves suppression resulted in cutting death. The cambium exposition not proportion vantage on root cutting herbaceous. For the gotten results it was observed that the interaction between lesion and leaf presence was not significant, indicating that these factors act of independent form in relation to the evaluated parameters. Cutting with base lesion presented addition of only $10 \%$ of foliar retention and percentage of roots cutting. Cutting with a pair of leaves had been superior to the parameters of the mass fresh and dry of root in relation to the cutting with half leaves, and the cutting without leaves not presented formation of roots being presence of leaves fundamental to roots promotion.
\end{abstract}

Key words: Psidium guajava L, growth regulator, propagation

\footnotetext{
1 Engenheira Agrônoma, Mestre e Doutoranda em Agronomia pela Universidade Estadual de Londrina (UEL) - Londrina-Pr; Cx. Postal 6001; E-mail: ph_santoro@yahoo.com.br, yatiem@gmail.com, silviahulse@yahoo.com.br

2 Prof. Adjunto do curso de Agronomia da Universidade Estadual de Londrina. E-mail: sroberto@uel.br

* Autor para correspondência
} 


\section{Introdução}

A goiabeira (Psidium guajava L.) é uma frutífera pertencente à família Myrtacea, a qual é composta por mais de 70 gêneros e 2800 espécies (DANTAS; DUTRA; KERSTEN, 1999). É cultivada principalmente nos países localizados em zonas tropicais e sub-tropicais. O Brasil possui destaque, ocupando o posto de maior produtor de goiabas vermelhas (INSTITUTO DE ECONOMIA AGRÍCOLA - IEA, 2006).

Esta fruteira pode ser propagada pelos processos sexual e assexual. Apesar da facilidade e velocidade de obtenção de mudas, a propagação por sementes, com finalidade de comercialização, não é recomendada devido à alta variabilidade genética, dificultando a fixação de características de interesse agronômico (GONZAGA NETO; SOARES, 1994). Pomares para fins de industrialização ou para exportação de fruta para consumo "in natura", devem apresentar plantas uniformes, bem formadas e produtoras de frutas com características botânicas e agronômicas bem definidas. Para isso é fundamental que se utilizem processos propagativos assexuais (TAVARES; KERSTEN; SIEWERDT, 1995).

Segundo Pereira e Martinez Júnior (1986) a enxertia e a estaquia são os métodos mais empregados na propagação vegetativa da goiabeira. Embora a enxertia, produza copas uniformes, os portaenxertos são oriundos de sementes, o que produz grande variabilidade (DANTAS; DUTRA; KERSTEN, 1999). Já a muda obtida através de estaquia supera esse problema eliminando a necessidade do uso de portaenxerto(KERSTEN; IBAÑEZ, 1993). Portanto, o enraizamento de estacas é uma alternativa para a propagação dessa espécie, uma vez que permite o início da produção num menor espaço de tempo, além da manutenção das características desejáveis selecionadas nas matrizes, no entanto este processo pode ser difícil e demorado (ONO; RODRIQUES, 1996).

Dentre as principais técnicas, que podem acelerar e aumentar o enraizamento de estacas de goiabeira pode-se destacar a presença de folhas e a realização de lesões na base das estacas. A preservação das folhas garante a sobrevivência das estacas, tanto pela síntese de carboidratos através da fotossíntese, como pelo fornecimento de auxinas e outras substâncias que são importantes no processo de formação de raízes, estimulando a atividade de troca e a diferenciação celular (ALVARENGA, 1990; FIGUEIREDO; KERSTEN; SCHUCH, 1995). A realização de lesões na base das estacas também pode aumentar o índice de enraizamento, pois, além de permitir maior absorção de água, faz com que haja o rompimento da barreira física exercida pelos anéis de esclerênquima. Isso resulta no aumento da taxa respiratória e nos teores de auxina, carboidratos e etileno na área lesionada, favorecendo a emissão de raízes (FACHINELLO et al., 1995).

A seleção 8501-9 é proveniente do cruzamento entre as cultivares 'Rica' e 'EEF-3' e foi selecionada pelo Programa de Melhoramento da Goiabeira da Faculdade de Ciências Agrárias e Veterinárias de Jaboticabal - UNESP. Esta seleção tem se destacado por possuir potencial produtivo e por ser tolerante ao ataque de psilídios (Hemiptera: Psyllidae), no entanto pouco se conhece sobre suas características em relação à propagação vegetativa por estaquia. Sendo assim, o presente trabalho teve por objetivo avaliar a influência da presença de folhas e o efeito da lesão basal no enraizamento de estacas herbáceas da seleção 8501-9 de goiabeira em câmara de nebulização, visando otimizar a produção de mudas.

\section{Material e métodos}

Os experimentos foram realizados no Departamento de Agronomia da Universidade Estadual de Londrina (UEL). Foram utilizadas estacas herbáceas da seleção 8501-9 de goiabeira (Psidium guajava L.), pertencente à coleção de goiabeiras da Fazesc - UEL. Foram estudadas duas formas de preparo das estacas (corte simples sem lesão e exposição do câmbio) e três intensidades de supressão das folhas (sem folhas, com folhas cortadas ao meio e folhas intactas). O delineamento 
experimental utilizado foi o inteiramente casualizado, com 4 repetições em arranjo fatorial 2 x 3, sendo que cada parcela foi composta por 10 estacas. Para o controle de doenças fúngicas, as estacas foram tratadas semanalmente com fungicida (i.a. mancozebe) por pulverização.

As estacas foram preparadas de modo a conterem dois nós com um par de folhas no nó superior e duas gemas tendo, em média, 10-12 cm de comprimento. Após a coleta as estacas foram dispostas provisoriamente em um recipiente com água para evitar a desidratação. A exposição do câmbio foi feita por meio de quatro cortes longitudinais opostos na porção basal das estacas, de aproximadamente 1 $\mathrm{cm}$ de comprimento e $2 \mathrm{~mm}$ de profundidade. Após o seu preparo, os diferentes tipos de estacas foram submetidos à aplicação de AIB na dose de $2000 \mathrm{mg}$ $\mathrm{L}^{-1}$ por imersão rápida (5 segundos) da sua porção basal.

Em seguida, as estacas foram imediatamente colocadas para enraizamento em caixas plásticas (44 x $30 \times 7 \mathrm{~cm}$ ) contendo casca de arroz carbonizada, em câmara de nebulização com regime intermitente controlado por temporizador e válvula solenóide. A válvula foi programada para nebulizar as estacas durante 10 segundos em intervalo de 3 minutos. O bico nebulizador empregado (Modelo Mist DanSprinklers, Israel) apresenta vazão de $35 \mathrm{~L}$ $\mathrm{h}^{-1}$. A câmara de nebulização encontra-se inserida em uma estufa agrícola com cobertura de filme de polietileno transparente e sombrite $30 \%$.

Após 78 dias do início do experimento, foram avaliadas as seguintes características: retenção foliar (\%); sobrevivência das estacas (\%); estacas enraizadas (\%); número de raízes por estaca; comprimento médio de raízes por estaca $(\mathrm{mm})$; massas fresca e seca de raízes por estaca $(\mathrm{g})$.

A partir dos dados obtidos avaliou-se o efeito dos fatores (lesão na base e presença de folhas) pela análise de variância e as médias comparadas pelo teste de Tukey a 5\% de probabilidade.

\section{Resultados e discussão}

O tratamento sem folhas resultou na não sobrevivência das estacas, gerando valores iguais a zero para todas as avaliações, comprometendo a homogeneidade e normalidade dos dados. Deste modo, o arranjo fatorial utilizado foi $2 \times 2$.

A interação entre a forma de preparo das estacas e presença de folhas não foi significativa, isso indica que estes fatores agem de forma independente no enraizamento de estacas herbáceas da seleção de goiabeira 8501-9 (Tabela 1).

A forma de preparo das estacas, quanto ao corte simples ou com exposição do câmbio, proporcionou diferença apenas na porcentagem de estacas enraizadas, para as demais variáveis avaliadas não houve diferença significativa. Desse modo, a exposição do câmbio proporcionou pouca vantagem no enraizamento das estacas de goiabeira, uma vez que apenas houve o incremento de $10 \%$ das estacas enraizadas (Tabela 1). Assim, não seria viável a realização das lesões devido o emprego de mais mão-de-obra, além de maior tempo no preparo das estacas. Wagner Júnior et al. (2004), verificaram que diferentes tipos de lesões na base de mirtilo (Vaccinium sp.) não influenciaram no enraizamento e no desenvolvimento das raízes de estacas herbáceas de quatro cultivares.

Normalmente as lesões na base com exposição do câmbio aumentam o enraizamento quando a estaca utilizada é do tipo lenhosa. Souza, Nachtigal e Kersten (1995), ao estudarem o enraizamento de estacas lenhosas de ameixa, verificaram que a lesão na base da estaca aumentou em $27 \%$ o enraizamento. Segundo Davis Júnior e Hartmann (1988), o aumento do teor de lignina nos tecidos exerce influência direta na capacidade de enraizamento das estacas, criando barreiras mecânicas ou fisiológicas. Assim, a realização de lesões na base das estacas faz com que haja maior absorção de água e de reguladores de crescimento, aumentando 
a eficiência de enraizamento. Isso pode explicar os resultados obtidos no presente trabalho, onde a presença de lesão nas estacas teve pouca influência no enraizamento, provavelmente pelo fato destas serem do tipo herbácea.

Para o fator intensidade de supressão das folhas, as estacas com um par de folhas inteiras e as estacas que tiveram o par de folhas cortado ao meio não diferiram entre si em relação à retenção foliar com 68,7 e 58,7 \% respectivamente (Tabela 1). Para estes dois tipos de estacas também não houve diferença quanto à porcentagem de estacas enraizadas, com $75 \%$ para estacas com folhas inteiras e $73,7 \%$ para folhas cortadas ao meio, sendo os valores obtidos considerados satisfatórios para a goiabeira. Os tratamentos com folhas inteiras e cortadas ao meio não apresentaram diferença significativa em relação ao número de raízes, comprimento e sobrevivência das estacas. Porém, a média de massa fresca e seca de raízes foi superior nas estacas com um par de folhas inteiras. As estacas sem folhas não apresentaram formação de raízes, tendo como conseqüência a não sobrevivência das mesmas. A maior massa de raízes pode influenciar diretamente o desenvolvimento da muda em viveiro e posterior transplantio a campo, devido à maior capacidade de absorção de água e nutrientes.

Tabela 1. Retenção foliar, sobrevivência de estacas e capacidade de enraizamento da seleção de goiabeira 8508-9 submetidas a duas formas de preparo das estacas (corte simples sem lesão e exposição do cambio) e duas intensidades de supressão das folhas (com folhas cortadas ao meio e folhas intactas).

\begin{tabular}{|c|c|c|c|c|c|c|c|c|}
\hline \multirow{2}{*}{\multicolumn{2}{|c|}{ Formas de preparo }} & \multirow{2}{*}{ RF (\%) } & \multirow{2}{*}{ SE $(\%)$} & \multicolumn{5}{|c|}{ Capacidade de Enraizamento } \\
\hline & & & & EE (\%) & NR & CR (mm) & MF (g) & MS (g) \\
\hline \multirow{2}{*}{\multicolumn{2}{|c|}{$\begin{array}{l}\text { Sem lesão } \\
\text { Com exposição do câmbio }\end{array}$}} & $56,2 \mathrm{a}$ & $67,5 \mathrm{a}$ & $66,2 \mathrm{~b}$ & $6,5 \mathrm{a}$ & $9,6 \mathrm{a}$ & $3,1 \mathrm{a}$ & $0,6 \mathrm{a}$ \\
\hline & & $71,2 \mathrm{a}$ & $82,5 \mathrm{a}$ & $82,5 \mathrm{a}$ & $7,5 \mathrm{a}$ & $9,8 \mathrm{a}$ & $3,1 \mathrm{a}$ & $0,7 \mathrm{a}$ \\
\hline \multicolumn{2}{|l|}{ Folhas cortadas ao meio } & $68,7 \mathrm{a}$ & $75,0 \mathrm{a}$ & $73,7 \mathrm{a}$ & $6,6 \mathrm{a}$ & $9,3 \mathrm{a}$ & $2,2 \mathrm{~b}$ & $0,5 \mathrm{~b}$ \\
\hline \multicolumn{2}{|l|}{ Folhas inteiras } & $58,7 \mathrm{a}$ & $75,0 \mathrm{a}$ & $75,0 \mathrm{a}$ & $7,4 \mathrm{a}$ & $10,7 \mathrm{a}$ & $4,0 \mathrm{a}$ & $0,9 \mathrm{a}$ \\
\hline Causas de variação & GL & & & & & & & \\
\hline $\begin{array}{l}\text { Lesão (L) } \\
\end{array}$ & 1 & $900 \mathrm{~ns}$ & $900 \mathrm{~ns}$ & $1056,25 *$ & $3,52 \mathrm{~ns}$ & $0,19 \mathrm{~ns}$ & $0,01 \mathrm{~ns}$ & $0,02 \mathrm{~ns}$ \\
\hline Folhas (F) & 1 & $400 \mathrm{~ns}$ & $0 \mathrm{~ns}$ & $6,25 \mathrm{~ns}$ & $2,20 \mathrm{~ns}$ & $2,14 \mathrm{~ns}$ & $13,35 *$ & $0,52 *$ \\
\hline Interação (LxF) & 1 & $225 \mathrm{~ns}$ & $100 \mathrm{~ns}$ & $156,25 \mathrm{~ns}$ & $5,10 \mathrm{~ns}$ & $0,20 \mathrm{~ns}$ & $0,00 \mathrm{~ns}$ & $0,00 \mathrm{~ns}$ \\
\hline Resíduo $^{1}$ & 12 & & & - & - & - & - & - \\
\hline CV\% & & 24,17 & 20,37 & 18,92 & 25,11 & 11,09 & 15,75 & 13,15 \\
\hline
\end{tabular}

RF- Retenção foliar (\%); SE- Sobrevivência das estacas (\%); EE- Estacas enraizadas (\%); NR- Número de raízes por estaca; CR- Comprimento médio de raízes por estaca (mm); MF- Massa fresca de raízes por estaca (g); MS- Massa seca de raízes por estaca (g); Médias seguidas das mesmas letras nas colunas não diferem entre si pelo Teste de Tukey $(\mathrm{p}<0,05)$. GL- Graus de liberdade; QMR- Quadrado médio do resíduo; ns- valores não significativos $(\mathrm{p}<0,05)$.

O efeito benéfico da presença das folhas em estacas para o enraizamento é atribuído à produção de auxinas e cofatores, que são transportados para a base das estacas e pelo processo da fotossíntese, responsável pela síntese de carboidratos necessários como fonte de energia para formação e crescimento das raízes (DAVIS, 1988). A importância da presença de folhas para o enraizamento também foi observada por Bordin et al. (2005), que não verificaram diferenças significativas entre estacas semi-lenhosas de portaenxertos de videiras com uma folha inteira e as com meia folha para a porcentagem de estacas enraizadas, número de raízes, matéria fresca e comprimento de raízes, no entanto, estas mesmas variáveis apresentaram valores inferiores para as estacas com ausência de folhas, sendo 90\% menores em relação à matéria fresca e comprimento de raízes. 
Para estacas de acerola Gontijo et al. (2003) verificaram que a presença de dois pares de folhas proporcionou maior porcentagem de enraizamento, número de raízes por estaca e massa seca, enquanto que as estacas sem folha não apresentaram formação de raízes. A não formação de raízes também foi observada por Biasi, Pommer e Pino (1997) para estacas de videira sem folhas, confirmando a fundamental importância da presença de folhas nas estacas para o enraizamento. Assim, é necessário que as folhas sejam preservadas durante todo o período de formação das raízes. Para isso deve-se selecionar na planta matriz de goiabeira, estacas que apresentem folhas inteiras e saudáveis, mantendoas sob nebulização e tratamentos fitossanitários.

\section{Conclusões}

A supressão das folhas resultou em não sobrevivência das estacas herbáceas da seleção 8501-9 de goiabeira.

A exposição do câmbio não proporcionou vantagens no enraizamento das estacas.

A presença de folhas inteiras promove maior massa fresca e seca das raízes das estacas, sendo fundamentais para a promoção do enraizamento.

\section{Referências}

ALVARENGA, A. A. Substâncias de crescimento e regulação do desenvolvimento vegetal. Lavras: UFLA, 1990.

BIASI, L. A.; POMMER, C. V.; PINO, P. A. G. S. Propagação de porta enxertos de videira mediante estaquia lenhosa. Bragantia, Campinas, v. 56, n. 2, p. 1-14, 1997.

BORDIN, I.; ROBERTO, S. R.; HIDALGO, P. C.; BÜRKLE, R. Efeito da presença da folha no enraizamento de estacas semilenhosas de porta-enxertos de videira. Ciência Rural, Santa Maria, v. 35, n. 1, p. 215-218, 2005.
DANTAS, A. C. M.; DUTRA, L. F.; KERSTEN, E. Influência do etefon e do tipo de estaca no enraizamento de goiabeira (Psidium Guajava L.). Revista Brasileira de Agrociência, Pelotas, v. 5, n. 1, p. 19-21, 1999.

DAVIS, T. D. Photosynthesis during adventitious rooting. In: DAVIS, T. D.; HAISSIG, B. E.; SANKHLA, N., (Ed.). Adventitious root formation in cuttings. Portland: Dioscorides Press, 1988. cap. 16, p. 214-234.

DAVIS JÚNIOR, F. T.; HARTMANN, H. T. The physiological basis of adventitious root formation. Acta Horticulturae, Wageningen, v. 227, n. 2, p. 113-120, 1988.

FACHINELLO, J. C.; HOFFMANN, A.; NACHTIGAL, J. C.; KERSTEN, E.; FORTES, G. R. L. Propagação de plantas frutiferas de clima temperado. 2. ed. Pelotas: EDUFPEL, 1995.

FIGUEIREDO, S. L. B.; KERSTEN, E.; SCHUCH, M. W. Efeito do estiolamento parcial e do ácido indolbutírico (AIB) no enraizamento de estacas de goiabeira serrana (Feijoa sellowiana Berg). Scientia Agrícola, Piracicaba, v. 52, n. 1, p. 167-171, 1995.

GONTIJO, T. C. A.; RAMOS, J. D.; MENDONÇA, V.; PIO, R.; ARAÚJO NETO, S. E.; CORREAA, F. L. O. Enraizamento de diferentes tipos de estacas de aceroleira utilizando ácido indolbutírico. Revista Brasileira de Fruticultura, Jaboticabal, v. 25, n. 2, p. 290-292, 2003.

GONZAGA NETO, L.; SOARES, J. M. Goiaba para exportação: aspectos técnicos da produção. Brasília: EMBRAPA, 1994.

INSTITUTO DE ECONOMIA AGRÍCOLA - IEA. A Cultura da goiaba em São Paulo. 2005. Disponível em: $\quad<$ http://www.iea.sp.gov.br/out/verTexto. php?codTexto=1902>. Acesso em: 24 nov. 2006.

KERSTEN, E.; IBAÑEZ, U. A. Efeito do ácido indolbutírico (AIB) no enraizamento de estacas de ramos de goiabeira (Psidium guajava L.) em condição de nebulização e teor de aminoácidos totais. Revista Brasileira de Fruticultura, Jaboticabal, v. 15, n. 1, p. 8789, 1993.

ONO, E. O.; RODRIQUES, J. D. Aspectos da fisiologia do enraizamento de estacas caulinares. Jaboticabal: FUNEP, 1996. $83 \mathrm{p}$.

PEREIRA, F. M.; MARTINEZ JUNIOR, M. Goiabas para industrialização. Jaboticabal: Legis Summa, 1986. $142 \mathrm{p}$. 
PEREIRA, F. M.; OIOLI, A. A. P.; BANZATO, D. A. Enraizamentos de diferentes tipos de estacas enfolhadas de goiabeira (Psidium guajava L.) em câmaras de nebulização. Científica, São Paulo, v. 11, n. 2, p. 239244, 1983.

SOUZA, C.; NACHTIGAL, J. C.; KERSTEN, E. Efeito da lesão e do ácido indolbutírico no enraizamento de duas cultivares de ameixeira (Prunus salicina, lindl) através de estaca. Revista Brasileira de Agrociência, Pelotas, v. 1, n. 3, p. 171-174, 1995.
TAVARES, M. S. W.; KERSTEN, E.; SIEWERDT, F. Efeitos do ácido indolbutírico e da época de coleta no enraizamento de estacas de goiabeira (Psidium guajava 1.). Scientia Agrícola, Piracicaba, v. 52, n. 2, p. 310-317, 1995.

WAGNER JÚNIOR, A.; COUTO, M.; RASEIRA, M. C. B.; FRANZON, R. C. Efeito da lesão basal e do ácido indolbutírico no enraizamento de estacas herbáceas de quatro cultivares de mirtilo. Revista Brasileira de Agrociência, Pelotas, v. 10, n. 2, p. 251-253, 2004. 